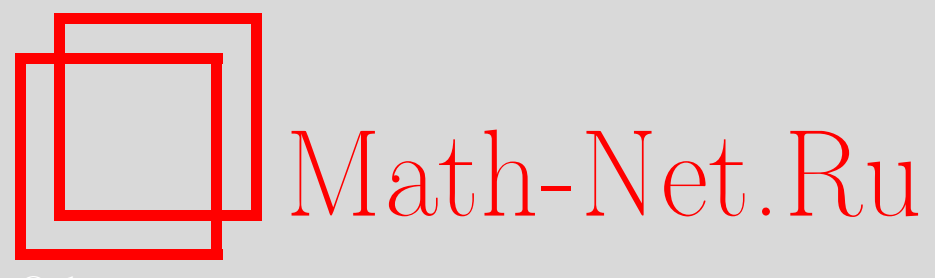

А. Варламов, Ж. Виллен, А. Ригамонти, Физика, геометрия и красота, Квант, 2020, номер 10, 2-6

DOI: https://doi.org/10.4213/kvant20201001

Использование Общероссийского математического портала Math-Net.Ru подразумевает, что вы прочитали и согласны с пользовательским соглашением http://www.mathnet.ru/rus/agreement

Параметры загрузки:

IP: 52.6 .47 .48

26 апреля 2023 г., $16: 11: 45$

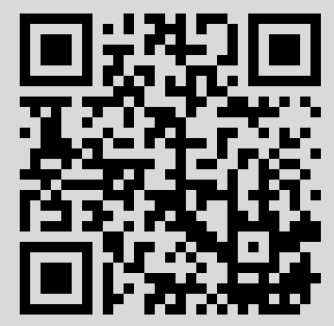




\section{Физика, геометрия и красота}

\section{А.ВАРЛАМОВ, Ж.ВИЛЛЕН, А.РИГАМОНТИ}

\section{K} АК НЕ ИЗУМЛЯТЬСЯ ТВОРЕНИЯМ природы? Эмоции переполняют нас при виде совершенной симметрии кристаллов или разнообразия фигур Хладни. Ученые тоже не остаются равнодушными к красоте природы. Луи де Бройль говорил о «таинственной красоте обличий, принимаемых электрическим разрядом» (речь, посвященная Жану Перрену, 1962). Гейзенберг, который выступил с докладом о «Значении красоты в точных науках» (Die Bedeutung Schönen in der exakten Naturwissenschaft), писал: «Внутренние связи [атомов в квантовой теории] в математических абстрациях демонстрируют невероятную степень простоты и красоты - дар, который нам остается только смиренно принять. Даже Платон не мог представить подобную красоту. Она не могла быть придумана, она существует с момента сотворения мира». А вот что полагал Эйнштейн: «Что же до простоты и красоты [природы], я отдаю должное эстетическим аспектам <...> Я преклоняюсь перед простотой и красотой математических моделей, созданных природой».

Следуя за великими физиками, заглянем в микромир и восхитимся некоторыми художественными творениями природы. В них задействован очень распространенный элемент - углерод.

\section{Метаморфозы углерода}

Итальянский писатель и химик Примо Леви (известный автобиографическими произведениями о своем пребывании в Освенциме) говорил об углероде: «Углерод - особый элемент, единственный, способный соединяться сам с собой и образовывать без большого расхода энергии длин-

DOI: https://doi.org/10.4213/kvant20201001 ные устойчивые цепи, а для жизни на Земле (той единственной формы жизни, которая нам известна) нужны как раз длинные цепи. Потому-то углерод и является ключевым элементом в создании жизни». Эти длинные углеродные цепи, к которым присоединяются атомы водорода, а иногда и кислород, азот, фосфор, являются основой молекул, составляющих химию живого мира. Например, белки и сахара или же такая совершенная молекулярная структура, как ДНК (рис.1).

Чистый углерод также обладает удивительными свойствами, о которых и не подозревал Примо Леви, когда писал эти строки в 1970 году. До недавнего времени (скажем, до 1990 года) учебники говорили

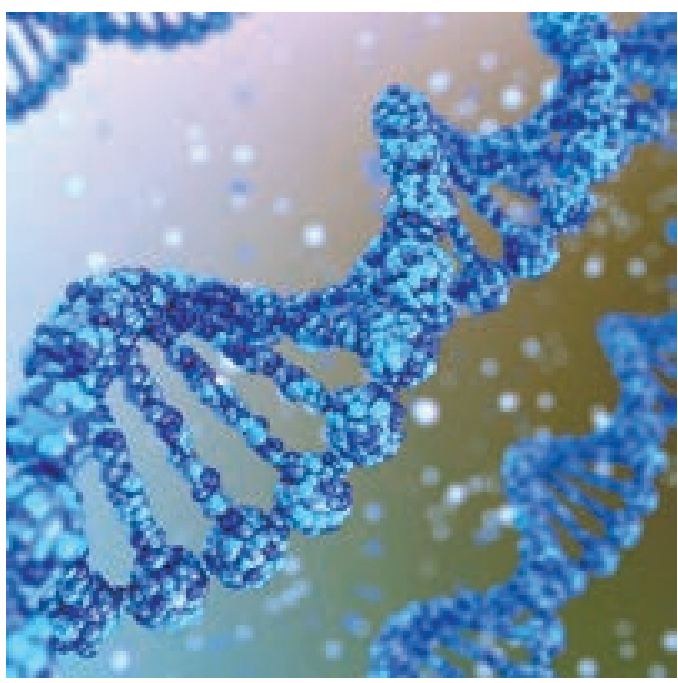

Рис. 1. Двойная спираль молекулы ДНК (дезоксирибонуклеиновой кислоты), которая кодирует генетическую информацию. Структура ДНК была выявлена спомощью рентгеновской дифракции. Молекула состоит из четырех типов нуклеотидов, которые комплементарно собраны на каждой нити, что дает ей возможность реплицироваться (возобновляться) 


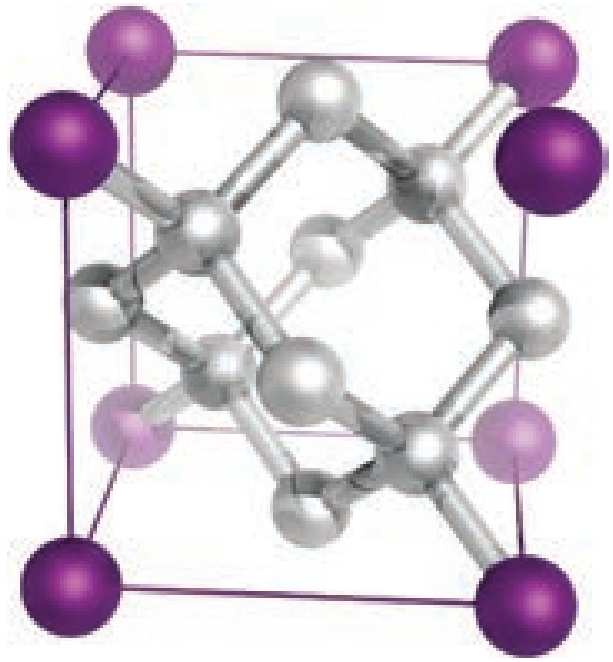

Рис. 2. Кристаллическая структура алмаза представляет собой гранецентрированную кубическую решетку, в которую включено четыре дополнительных атома углерода. Каждый атом окружен четырьмя соседями, которые образуют правильный тетраэдр

о существовании двух кристаллических модификаций углерода - довольно распространенного графита и алмаза.

Алмаз - редко встречающийся кристалл, крупные образцы которого может создавать только природа при экстремальных температурах и давлениях. И все же химически алмаз являет собой самую простую модификацию углерода (рис.2): в ней каждый атом имеет четырех соседей, с которыми образует очень прочные химические связи, называемые ковалентными. Стремление атома углерода иметь четырех соседей - результат довольно простых законов химии. Действительно, в атоме углерода, шестого элемента периодической таблицы, имеется шесть электронов. В упрощенной модели электроны распределяются вокруг ядра по оболочкам. Два ближайших к ядру электрона образуют «замкнутую оболочку»: они химически инертны. Остальные четыре электрона находятся на второй, более удаленной от ядра оболочке. Однако на ней хватило бы места и для восьми электронов, а атомы, как правило, стремятся иметь такую электронную структуру, чтобы их внешняя оболочка была заполненной. Это найден- ное химиками древности «правило октета» (или, для самых легких элементов, «правило дуэта») - закон, который современные ученые объясняют с помощью квантовой механики. Ради его соблюдения атомы готовы получать или терять электроны, образуя ионы, или делить электроны с другими атомами, создавая ковалентные связи.

В алмазе каждый из четырех электронов внешней оболочки соединяется с электроном внешней оболочки другого атома с образованием четырех связей $\mathrm{C}-\mathrm{C}$, и, таким образом, правило октета оказывается соблюденным. Итак, каждый атом в алмазе имеет четырех соседних. Полученная таким образом структура оказывается невероятно прочной, и поэтому алмаз является очень твердым веществом.

Как мы уже упоминали, алмаз - редкая модификация углерода. По прихоти химии атомы углерода более склонны образовывать двумерную структуру, в которой каждый из них связывается только с тремя другими. Таков двумерный кристалл графен (рис.3). Оставшийся незадействованным четвертый электрон внешней оболочки (один на атом) готов участвовать в формировании слабой связи, которая соединяет между собой один слой графена с другим, другой с третьим и т.д. В результате такой упаковки формируется графит - наиболее распространенная форма кристаллического углерода (рис.4). Это твердое темное вещество может служить,

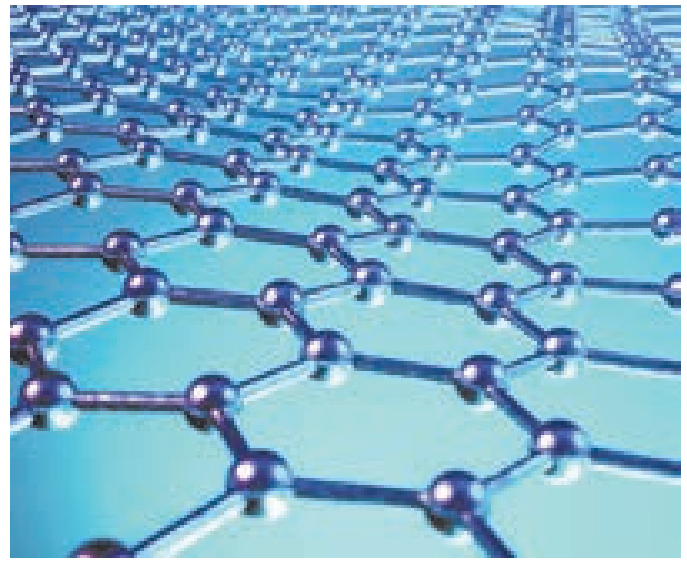

Рис. 3. Графен состоит из атомов углерода, образующих решетку в виде сот 


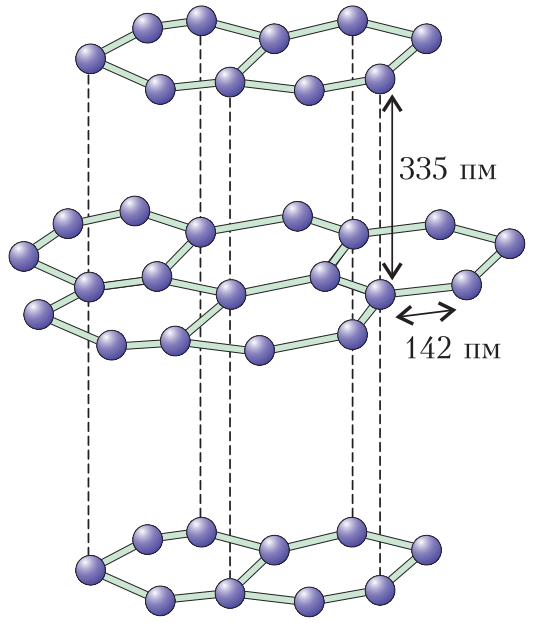

Рис. 4. Графит состоит из совокупности слабо связанных между собой слоев графена (эти слабые связи изображены пунктиром)

например, в качестве грифеля в обычном карандаше.

Соединяющие между собой слои графита слабые связи оказываются непрочными, и их довольно легко разорвать. Например, наклеивая на графит скотч и отрывая его, легко несколько слоев отделить; повторив такую процедуру несколько раз, в конце концов можно получить и единичный слой графена. Этот простой и нашедший широкое применение метод принес в 2010 году Нобелевскую премию по физике Андрею Гейму и Константину Новоселову.

Часто электрон внешней оболочки, не находящий себе ковалентной связи, немного усиливает три связи своих собратьев с электронами соседних атомов. Вместо того чтобы упаковываться с другими слоями в трехмерный графит, слой графена деформируется, переставая быть плоским, и спонтанно образует необычные структуры. Опишем некоторые из них.

\section{Когда углерод играет в футбол}

В результате наблюдений и анализа исследователи в разных частях мира пришли к выводу, что в саже и пламени свечи появляется небольшое количество специфического вещества, молекулы которого состоят из 60 атомов углерода $\left(\mathrm{C}_{60}\right)$. Атомы углерода в нем связываются так, что
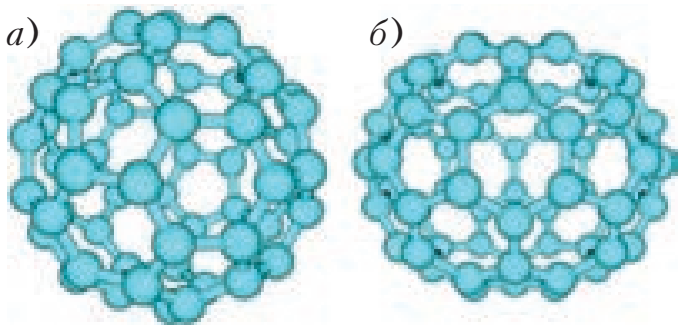

Рис. 5. а) Молекула $\mathrm{C}_{60}$ воспроизводит форму футбольного мяча, который состоит из кожаных пяти- и шестиугольников. б) Молекула $\mathrm{C}_{70}$ отдаленно напоминает мяч для регби

образуют 20 шестиугольников и 12 пятиугольников, воспроизводя таким образом форму футбольного мяча (рис.5, $a$ ).

Впоследствии, после открытия молекулы $\mathrm{C}_{60}$, в природе были обнаружены или синтезированы и другие, более крупные, молекулы, также состоящие из шести- и пятиугольников. Так, например, молекула $\mathrm{C}_{70}$ скорее имеет форму мяча для регби: она состоит из 25 шестиугольников и 12 пятиугольников (рис.5,б). К таким молекулам относится и гигант $\mathrm{C}_{540}$ (рис.6), который довольно легко получается путем испарения графита посредством облучения лазерным импульсом или дугового разряда. Такие молекулы, возможно, могут входить в состав межзвездной пыли.

Все эти молекулы, принимающие форму выпуклых многогранников и имеющие формулу $\mathrm{C}_{2 n}$, где $n$ - целое число, могут

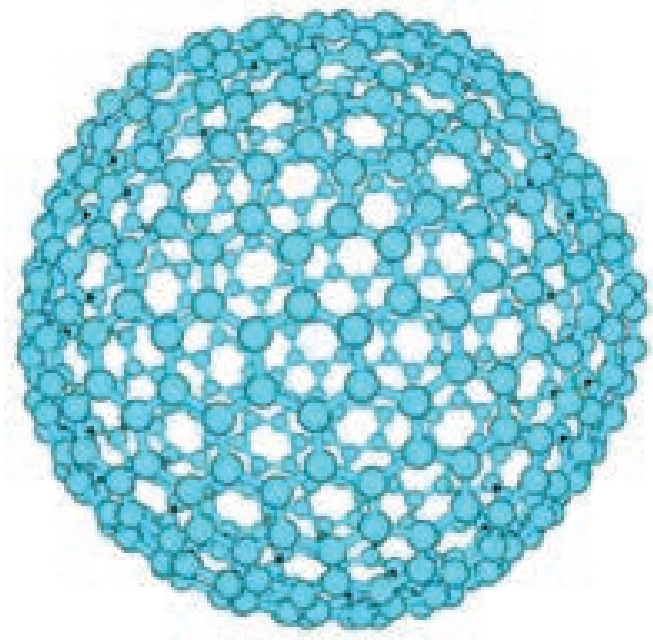

Рис. 6. Молекула $\mathrm{C}_{540}$ 
содержать разное число шестиугольников, но всегда 12 пятиугольников. Как это объяснить?

Пусть $h-$ количество шестиугольников и $p$ - количество пятиугольников. Согласно справедливой для многогранников теореме Эйлера, при условии, что выпуклый многогранник имеет $f$ граней, $s$ вершин и $a$ ребер, эти три числа должны удовлетворять формуле $f+s=a+2$. Числа $f, s$ и $a$ легко находятся из количества шести- и пятиугольников ( $h$ и $p$ соответственно). Прежде всего очевидно, что $f=h+p$. И поскольку каждый шестиугольник имеет шесть ребер, каждый пятиугольник их имеет пять, а каждое ребро является общим для двух сторон, то находим, что $a=(6 h+5 p) / 2$. Для нахождения числа вершин $s$ следует заметить, что каждая из них является общей для трех граней: соединить их большее число в вершине не представляется возможным, а принять $s=2$ - абсурдно. Каждый шестиугольник имеет шесть вершин, каждый пятиугольник - пять, а каждая вершина является общей для трех сторон; следовательно, $s=(6 h+5 p) / 3$. Подставляя найденные значения в формулу Эйлера, получим $p=12$. Заметим, что существует многогранник с 12 пятиугольниками и совсем без шестиугольников - правильный додекаэдр, который соответствует молекуле $\mathrm{C}_{20}$, самой маленькой в этом семействе. Что касается того, что все грани или шести-, или пятиугольные, это неудивительно: к примеру, квадратная грань требовала бы, чтобы две связи C-С образовывали между собой прямой угол, в то время как внешние электроны, как правило, распределяются в пространстве вокруг атомов симметрично.

Молекулы, которые мы только что описали, называются фуллеренами - в честь американского архитектора Бакминстера Фуллера, создателя геодезических куполов, напоминающих молекулу $\mathrm{C}_{60}$. Она была обнаружена первой; ее еще называют footballen из-за сходства с футбольным мячом. По сей день физики находят и исследуют потрясающе красивые структу-

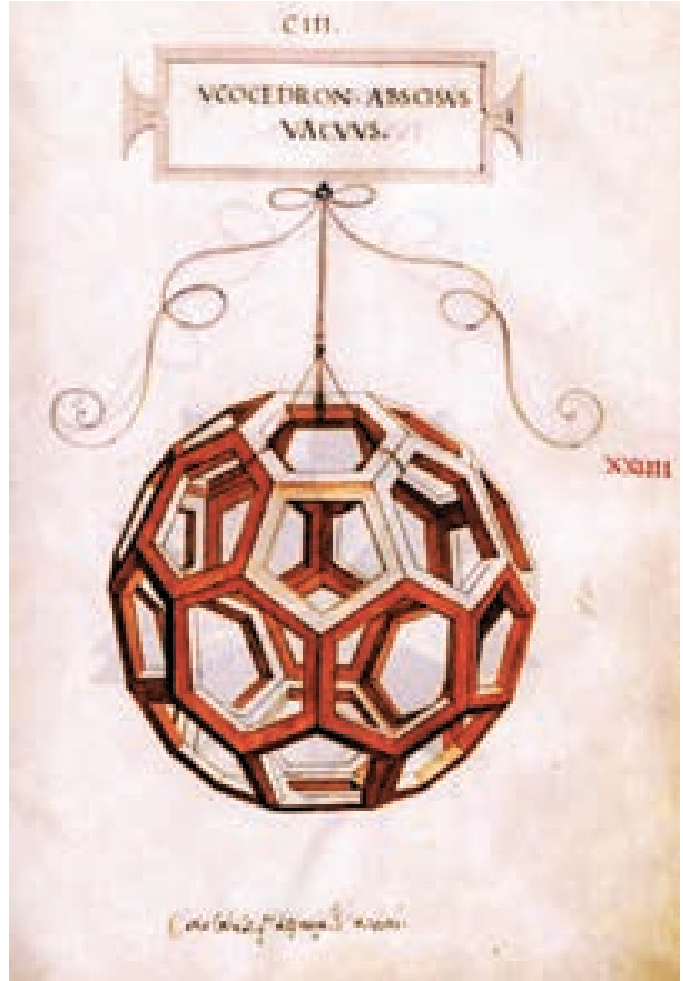

Рис. 7. Усеченный икосаэдр, изученный Пьеро делла Франческой и нарисованный Леонардо да Винчи для книги Луки Пачоли

ры, созданные природой и обычно скрытые от нас, а ведь некоторые художники их предсказали! Известный тосканский художник Пьеро делла Франческа (умерший в возрасте почти 80 лет в 1492 году), вероятно, был первым, кто изобразил футбольный мяч - или, вернее, усеченный икосаэдр, полученный в результате усечения обычного икосаэдра по пяти плоскостям. Пьеро делла Франческа увлекался математикой, но рисунок усеченного икосаэдра был обнаружен не в его «Книжице о пяти правильных телах», а в труде, опубликованном в 1510 году одним из его учеников, Лукой Пачоли. Иллюстратором книги, озаглавленной «Божественная пропорция», был... Леонардо да Винчи (рис.7).

\section{Углеродные нанотрубки}

Углерод также способен скручиваться, формируя трубки. Они бывают самых разных форм и размеров, диаметром от 

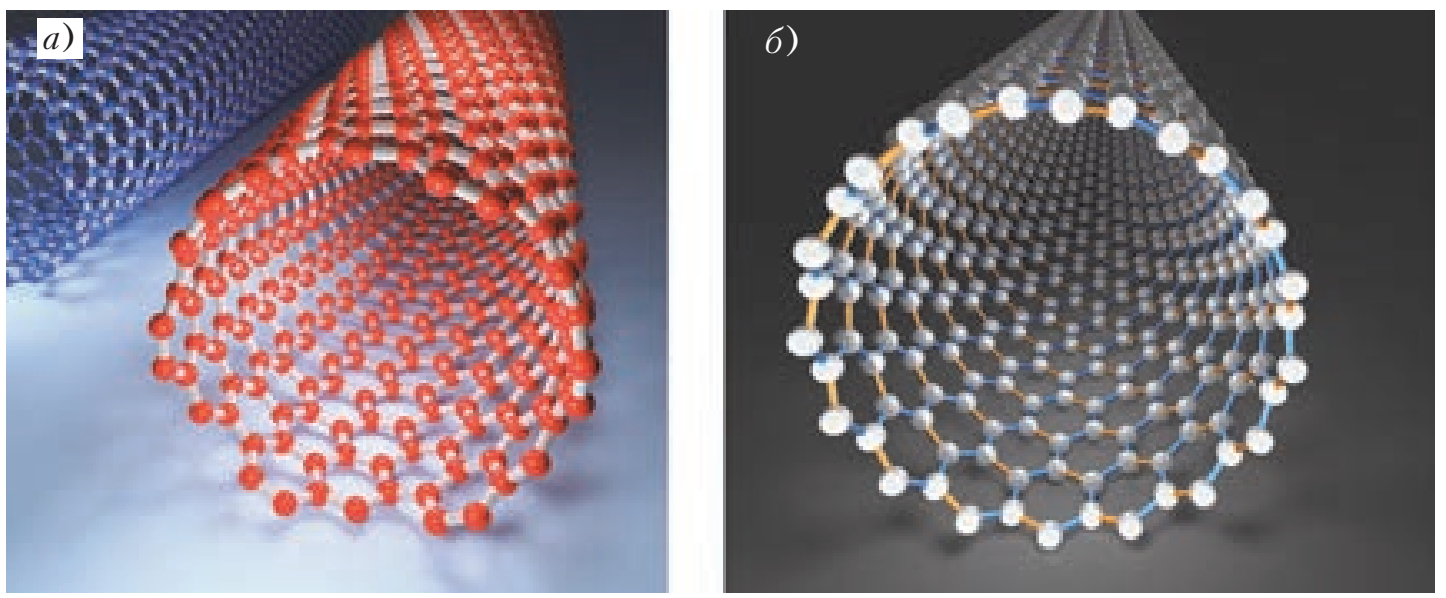

Рис. 8. Две разновидности углеродных нанотрубок. а) Конструкция "кресла» имеет связи, перпендикулярные оси трубки. б) “Зигзагообразная» структура обладает связями, параллельными оси трубки

одного до нескольких десятков нанометров (рис.8). Углеродные нанотрубки создают в лабораториях различными способами: отрывая кусочки от углеродного блока при помощи лазера или электрической дуги или же путем осаждения подходящего углеродного пара. На самом деле мы, сами того не зная, производили их на протяжении веков, но только с появлением усовершенствованных инструментов сумели обнаружить эти нанообъекты.

Нанотрубки, фуллерены и другие производные графена обладают электрическими и оптическими свойствами, которые будоражат умы физиков и в перспективе могут найти уникальные применения, скажем в фотоэлементах. Графеновая элект- роника также обещает продлить действие закона Мура, позволив создавать транзисторы еще меньшего размера, чем используемые сегодня кремниевые.

Нанотрубки имеют еще и замечательные механические свойства: они чрезвычайно устойчивы к растяжениям. Поэтому вскоре мы сможем увидеть легкие и прочные велосипеды и теннисные ракетки, созданные из композитных материалов, армированных углеродными нанотрубками диаметром в несколько микрон. Еще одна метаморфоза этого «особого элемента», воспетого Примо Леви!

Статья представляет собой главу из книги «Физика повседневности», выпущенной издательством «Альпина нон-фикшн» в 2020 году.

\section{Вниманию наших читателей}

Начиная с 2017 года журнал «Квант» стал ежемесячным и в год выходит 12 номеров журнала.

Подписаться на наш журнал можно с любого номера в любом почтовом отделении. Наш подписной индекс в каталоге "Пресса России» - 90964.

Купить журнал "Квант» возможно в магазине "Математическая книга» издательства МЦНМО (адрес интернет-магазина: biblio.mccme.ru), а также в московских книжных магазинах "Библио-глобус», "Молодая гвардия», "Московский дом книги» и в редакции журнала.

Архив вышедших номеров журнала “Квант» имеется на сайте http:/ / kvant.ras.ru 